\title{
Studying the Changes in Solar Radiation and Their Influence on Temperature Trend in Iraq for a Whole Century
}

\author{
Basim Abdulsada Al-Knani ${ }^{*}$ \\ Iqbal H. Abdulkareem ${ }^{2}$ \\ Hussain Abodi Nemah ${ }^{1}$ \\ Zahraa Nasir ${ }^{1}$ \\ ${ }^{1}$ Department of Atmospheric Sciences, College of Science, Mustansiriyah University, Baghdad, Iraq. \\ ${ }^{2}$ Faculty of Graduate Studies, University of Babylon, Baghdad, Iraq. \\ *Corresponding author: basim.a.s@uomustansiriyah.edu.iq ${ }^{*}, \quad \underline{\text { iqbal.baraznji@uobabylon.edu.iq, }}$ \\ Husain_abodi.atmsc@uomustansiriyah.edu.iq, zahraanasir10@gmail.com \\ *ORCID ID: https://orcid.org/0000-0001-9214-624X ${ }^{*}$ https://orcid.org/0000-0001-6956-9922, https://orcid.org/0000- \\ 0003-4621-4760, https://orcid.org/0000-0001-6934-7221
}

Received 5/10/2020, Accepted 15/4/2021, Published 20/6/2021

This work is licensed under a Creative Commons Attribution 4.0 International License.

\begin{abstract}
:
Most studies indicated that the values of atmospheric variables have changed from their general rates due to pollution or global warming etc. Hence, the research indicates the changes of direct solar radiation values over a whole century i.e. from 1900 to 2000 depending on registered data for four cities, namely (Mosul - Baghdad - Rutba - Basra. Moreover, attemptsto correlate the direct solar radiation with the temperature values have been recorded over that period. The results showed that there is a decreasing pattern of radiation quantities over time throughout the study period, where the value of direct radiation over the city of Baghdad $5550 \mathrm{w} / \mathrm{m}^{2}$ was recorded in the year 1900 , but this ratio decreased clearly to approximately 5400 $\mathrm{w} / \mathrm{m}^{2}$ in the year 2000, which is perhaps due to the increase of general pollution rates in the atmosphere. The results also showed that the city of Rutba recorded the highest annual rate of radiation quantities, and Baghdad with Mosul recorded the lowest radiation ratios compared to the rest of the cities, in addition to that there was a large convergence of radiation ratios between them to some extent. The results showed that there is a sharp drop in radiation ratios, specifically in the years1980and 1990. As for the extent of the relationship for solar radiation with temperature levels throughout the study period, it was found that there is an inverse relationship between them, and this confirms that the cause of high temperatures is not because of increased solar radiation, but it may rather due to other reasons such as increased greenhouse gases.
\end{abstract}

Key words: Direct solar radiation, Global warming, Iraq, Radiation fluctuation, Temperature trend.

\section{Introduction:}

Solar radiation is considered as the main source of energy that reaches the earth surface, where the sun emits its energy to the space in the form of electromagnetic radiation with a speed of light and this emitting needs about 8 minutes to reach earth outer atmosphere, some of this radiation reflects backward to space (1).

The energy emitted by sun covers a wider range of wavelengths (extended from shorter length to long wavelengths) and is divided into three main regions; infrared radiation band (between 4 and 0.7 micrometer), the second one is the visible region (between 0.7 and 0.4 micrometer) which represents (44\%) of the solar spectrum, and the third main region is called ultraviolet radiation band (between 0.4 and 0.2) (2).There were many factors effectingon solar radiation thatthat reflected radiation causedby changing the path into opposite way affectedby some obstacles, as well as scattered radiation deflected into many surrounding directions caused by scattering and absorption factors (3). Many studies conclude that many factors were having a wide effect on solar radiation ratio, such as cloud covers because the fully cloudy days consist of scattered radiation, and the ratio of scattered radiation is greater in winter as compared with summer in higher latitudes sunny regions (4).

It is very important to know that the change in temperature values will be an effect of geopotential height values, therefore this will effect on the weather because of expanding and 
compression of air that happen when the temperature rise or drops respectively (5).

It was mentioned that the clear sky sunny days consist of $85 \%$ of direct radiation from total radiation value, and the ratio of scattered radiation is only $15 \%$ of total radiation, this informs that weather condition widely effects on solar radiation transport (6).

There were many studies that deal with solar radiation because of its importance, from these studies the scientists Bishop and Rossow in 1991tried to study the spatial and temporal variation of solar radiation by using of 'NASA' satellite images for various regions along the earth surfaces, they found that there was a high accuracy of daily, monthly, and annual calculated values, also they found that the latitudinal location is largely corresponding on this accuracy (7).

Bernard in 2003investigatedthe solar radiation effects on building in 'Malawi city', to get the better direction of buildings with less effect of solar radiation heating to increase the efficiency of cooling systems that operate on it, he also found that the direct radiation is the most affected radiation type (8).

Benjamin in 2008suggested a new way of getting data by mixing satellite data with numerical models data that depends on orographic nature to estimate the spatial and temporal variation of solar radiation in the surrounding of 'Porto city France' (9).

Al-Salihi and others in 2010were trying to study the solar radiation over horizontal surfaces of three selected regions from Iraq depending on some meteorological variables including solar radiation with temperature and relative humidity, they discovered that there was a highly accurate correlation coefficient between solar radiation and other meteorological parameters with little error ratio (10).

Hazem, H. in 2019studied the change in temperature fluctuation over seasons and the shift of timing for all seasons of Iraq in order to show the effect of climate change on seasonal starting dates, and then he compared it with the past to calculate the value of shifting (11).

So this study aims to understand the real behavior of direct solar radiation for a long period of time in order to show its trends and to correlate it with temperature trends along the same period over Iraq.

\section{Materials and Methods:}

The study depends on actually huge data obtained from long period calculation extended to more than a complete century given from the department of atmospheric science in al Mustansiriyah university.These data have been recorded daily meaning direct solar radiation and temperature including minimum and maximum value of temperature. The averages were calculated from these daily data for every ten years separately including all seasons to get decadal average data of temperature and direct solar radiation of four selected cities(Baghdad, Rutba, Mosul, Basra) in order to cover a wider area of 'Iraq' as it is shown in Fig. 1.Charts were drawn showing the behavior over one century 100 yearsfor the period from 1900to the year 2000. Then the study made statistical relation diagrams between the two variables to understand the behavior of direct solar radiation along the study period and connect it with temperature trends for the same time.

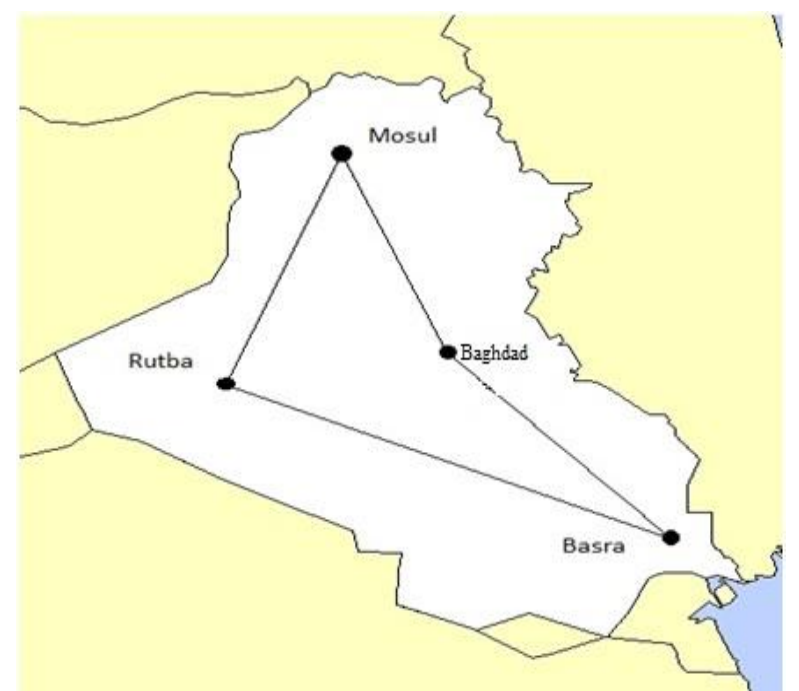

Figure 1. Study region showing the four selected cities.

\section{Results and discussion:}

After arranging the data for direct radiation quantities over Iraq and for numbers of points, the results showed that there is a clear fluctuation over the years but with a decreasing pattern over time, and that is very clear for the four points chosen in the study (Baghdad - Mosul Basra - Rutba) mentioned in Fig. 1.

The resulted ofFigs. 2, 3, 4 and 5 are showing that there is a clear decline in the values of direct radiation to approximately $(5000) \mathrm{w} / \mathrm{m}^{2}$ or less in the years (1980) and (1990) and for all points mentioned above, also in general there is a similarity in direct radiation behavior to some extent between the four points, but when comparing the four shapes, it is found that the city of Rutbahas radiation levels of approximately (5550) $\mathrm{w} / \mathrm{m}^{2}$, which is higher in comparison with the values of the other three points, where Basra follows it which 
reaches approximately $5520 \mathrm{w} / \mathrm{m}^{2}$, and therefore it has a higher radiation rate compared to Baghdad and Rutba cities which are similar in the rates of direct radiation values, this is evident by observing Fig. 6 . Some studies refer to that there is a variation in weather patterns along the last three decades due to climate change and that in role effects on solar radiation activity crossing the atmosphere causing the change in atmospheric pressure level (5).

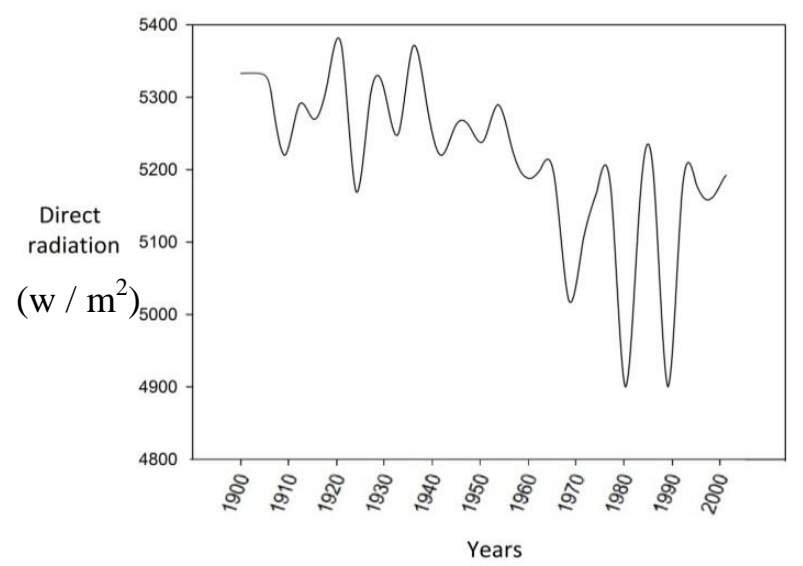

Figure 2. Direct solar radiation fluctuation over

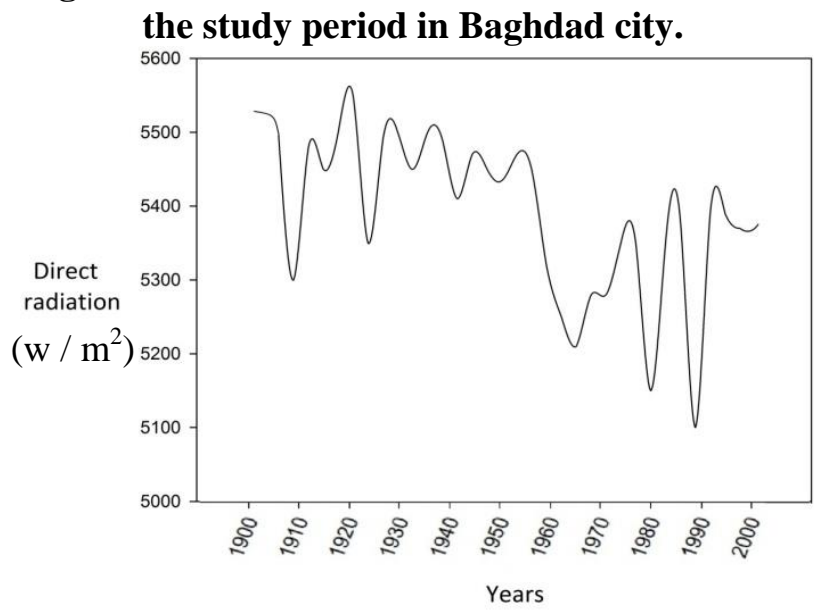

Figure 3. Direct solar radiation fluctuation over

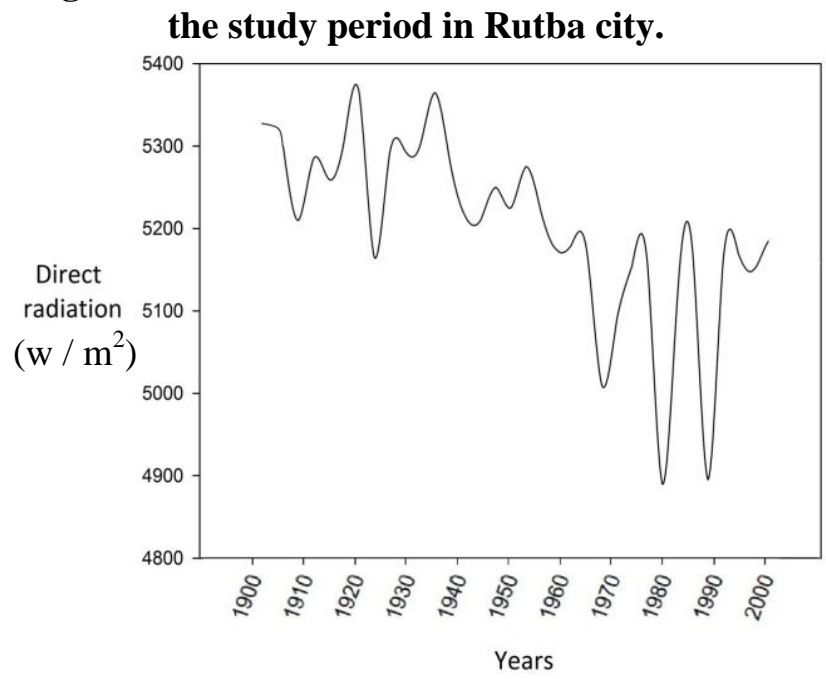

Figure 4. Direct solar radiation fluctuation over the study period in Mosul city.

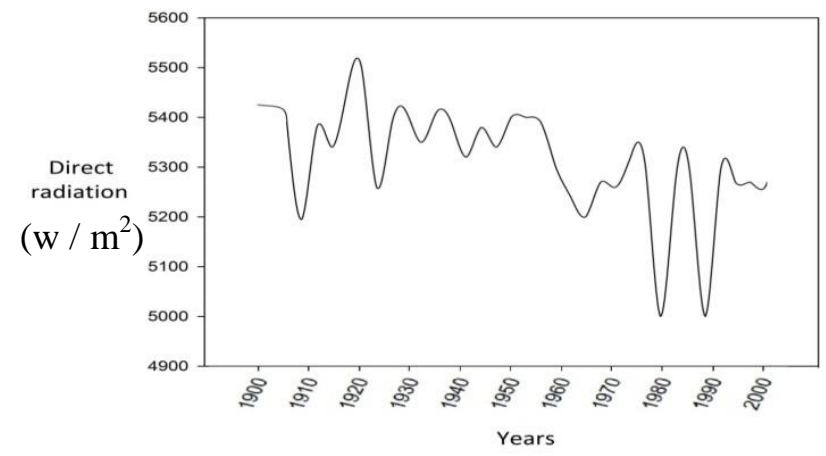

Figure 5. Direct solar radiation fluctuation over the study period in Basra city.

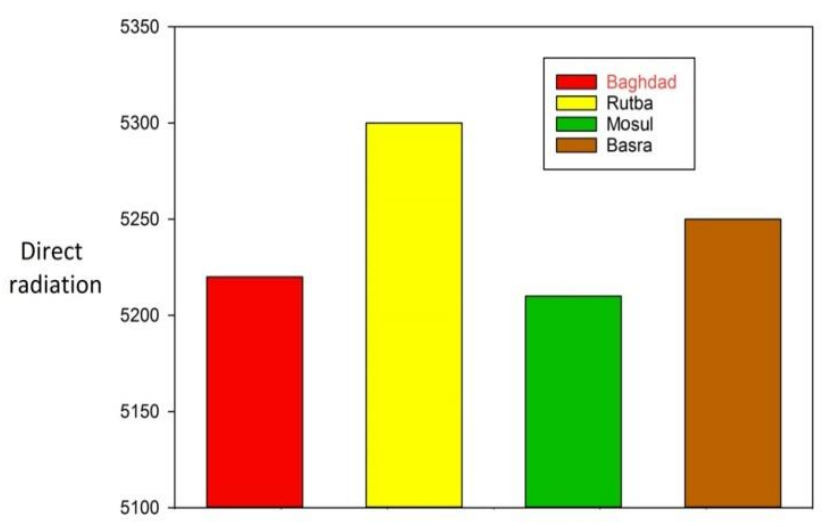

Figure 6. Comparison of direct solar radiation fluctuation amount between the four study cities.

Also, the data has been obtained regarding temperature over Iraq for the same period and for the four citieschosen to indicate the relationship between these two variables. It has been shown that there is a relationship between the quantities of direct radiation reaching the surface and the average temperature throughout the study period, as all four Figs 7, 8, 9, and 10 show that there is an inverse relationship between temperature and direct solar radiation trend over the whole study period, so the increase in temperature over time is matched by a decreasing pattern of direct solar radiation, which may be due to another factor, which is the increase in the concentrations of air pollutants such as $\mathrm{CO} 2$ resulting from the industrial revolution that in turn led to an increase in global warming on one hand, as well as attenuation of direct radiation ratios on the other hand. These consequently two different reactions (increasing temperature rates - decreasing direct radiation levels reaching the surfaceare leading to opposite results. There is a study that confirms that the temperature values have increased from their averages over a whole century and that this increase is accompanied by a change in the dates of the four seasons compared to the previous one (11). 


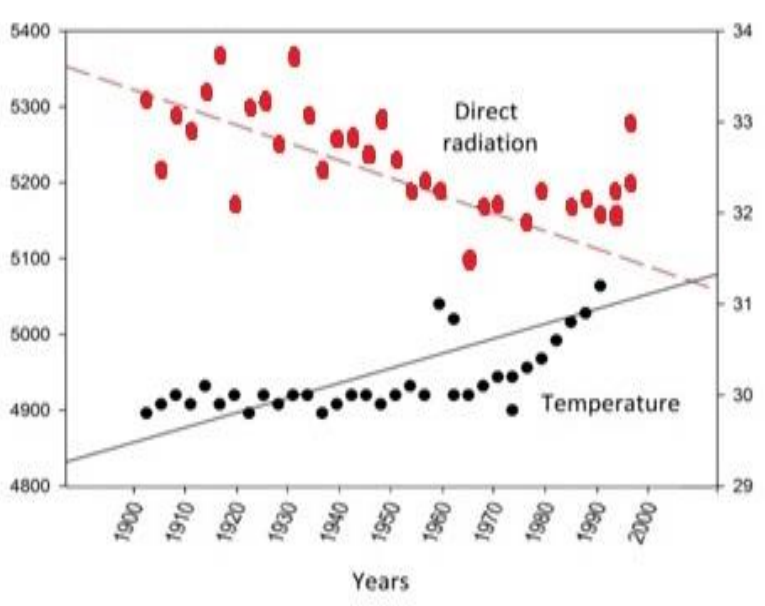

Figure 7.Relationship between temperature and direct solar radiation trend over the whole study period for Baghdad city showing the trend lines.

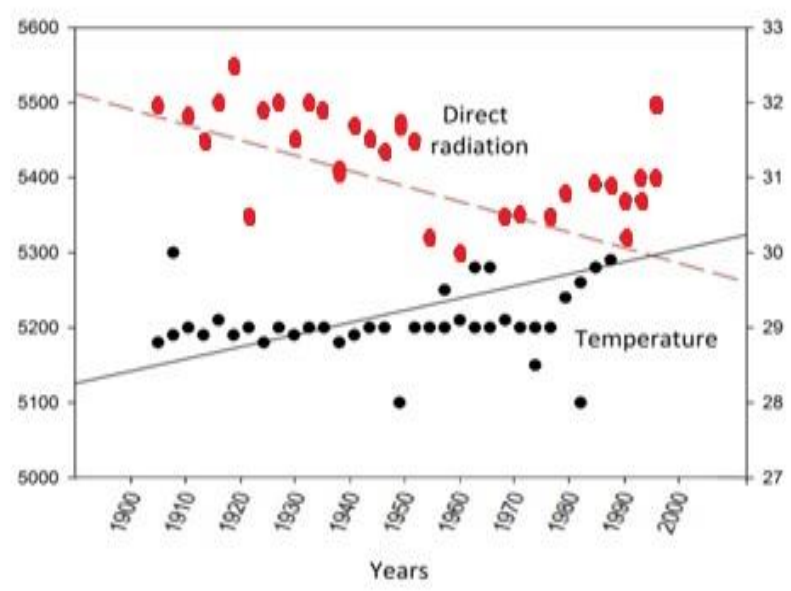

Figure 8.Relationship between temperature and direct solar radiation trend over the whole study period for Rutba city showing the trend lines.

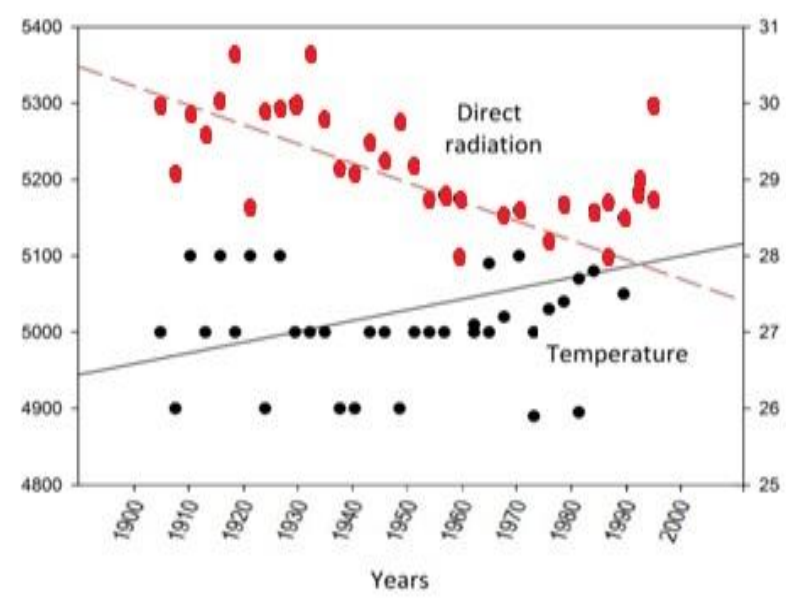

Figure 9.Relationship between temperature and direct solar radiation trend over the whole study period for Mosul city showing the trend lines.

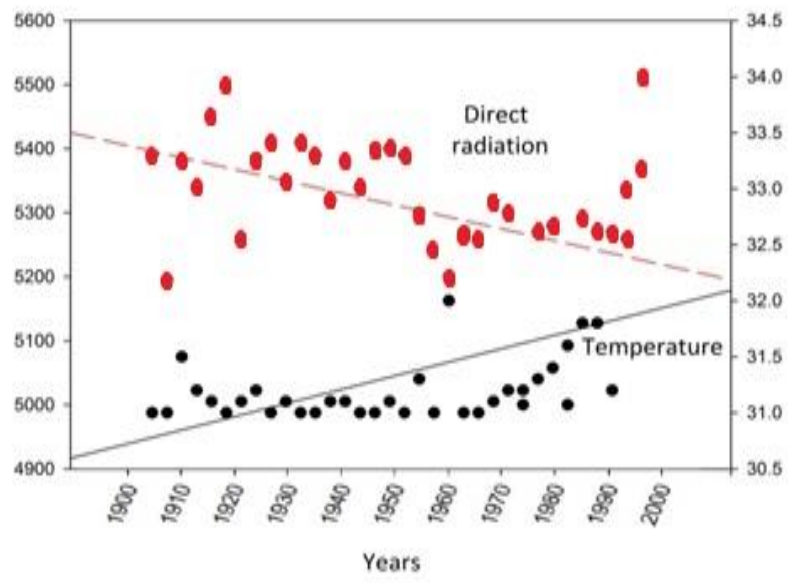

Figure 10.Relationship between temperature and direct solar radiation trend over the whole study period for Basra city showing the trend lines.

\section{Conclusion:}

This study concludes that direct solar radiation values arefluctuating over Iraq from one city to another, and the higher recorded value isover Rutba city. It is noted that a decreasing trend of direct solar radiation is along all past century, especially in the last (30) years with a high drop-in (1980) and (1990). Through the temperature and direct solar radiation values compared, it is clearly shown that an inverse relation between them, where this may relate to the increase in pollutant and gases intensity as a result of the industrial revolution, so this leads to make blocking radiation and increasing of temperatures.

\section{Acknowledgment:}

We appreciate the cooperation of the Department of Atmospheric Sciences in cooperating and providing the appropriate environment for scientific research.

\section{Authors' declaration:}

- Conflicts of Interest: None.

- We hereby confirm that all the Figures and Tables in the manuscript are mine ours. Besides, the Figures and images, which are not mine ours, have been given the permission for republication attached with the manuscript.

- Ethical Clearance: The project was approved by the local ethical committee in Mustansiriyah University.

\section{References:}

1. AkittJ W, Some observations on the greenhouse effect at the Earth's surfaceSpectrochim. Acta A Mol. Biomol. Spectrosc. 2018; 188: 127-134.

2. Bhushan, M, Jha R, Bhardwaj R. Reduced band gap and diffusion controlled spherical n-type $\mathrm{ZnS}$ 
nanoparticles for absorption of $\mathrm{UV}-\mathrm{V}$ is region of solar spectrum. J Phys Chem. Solids.2019;135: 109121.

3. Van den Berg $\mathrm{T} J$. Intraocular light scatter, reflections, fluorescence and absorption- what we see in the slit lamp.OpththalPhysl Opt. 2018; 38:6-25.

4. Huang L, Deng L, Li A, Gao R, Zhang L, Lei W. Analytical model for solar radiation transmitting the curved transparent surface of solar greenhouse. JBuild Eng. 2020;32: 101-120.

5. Wedian G, Hussain A, Basim A. Study of geopotential height values and its ineraction with temperature degree over Iraq.Plant Arch. 2020;20: 1317-1322.

6. Ruiz-Arias JA, GueymardC A. Worldwide intercomparison of clear-sky solar radiation models: Consensus-based review of direct and global irradiance components simulated at the earth surface. Sol Energy.2018; 168: 10-29.
7. Bishop J,Rossow W. Spatial and temporal variability of global surface solar irradiance.J Geophys Res. 1991; 96:16839-16858.

8. Bernard W, Effects of solar radiation on building and thermal comfort, Ph.D. Thesis, University of Hertfordshire. 2003;4: 31-51.

9. BoisB, Wald L, Pieri P, Van Leeuwen C, Commagnac L, Chery P,et al.estimating spatial and temporal variations in solar radiation within Bordeaux winegrowing using remotely sensed data. J Int Sci Vigne Vin. 2008; 42: 15-25.

10. AL-Salihi A, Mayla M, Ali J,Estimation of Global Solar Radiation on Horizontal Surface Using Routine Metrological Measurements for Different Cities in Iraq.Asian J Sci Res. 2010; 8: 240-248.

11. Hazem HH, Hussain A N, Basim A.estimating seasonal starting points as a result of climate change impaction.Plant Arch. 2019; 19: 1525-1528.

\section{دراسة تغيرات الإثعاع الثمسي المباشر وتأثير ها على نمط درجات الحرارة في العراق لمدة قرن كامل \\ حسين عبودي 1 \\ اقبال حسين 2 \\ باسم عبدالسادة 1

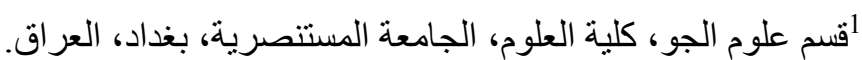

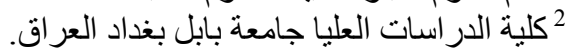

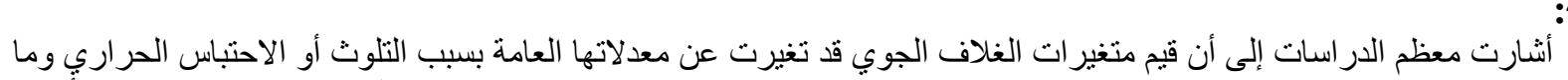

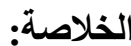

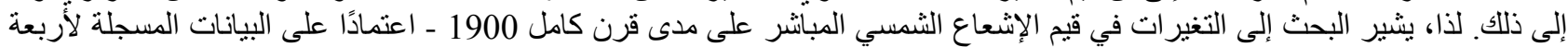

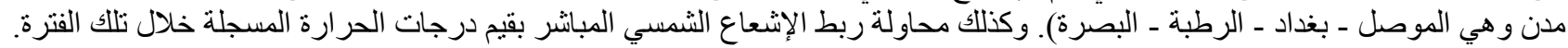

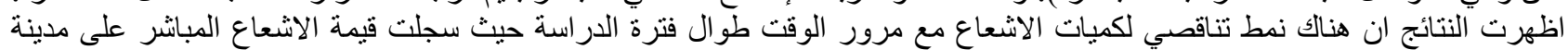

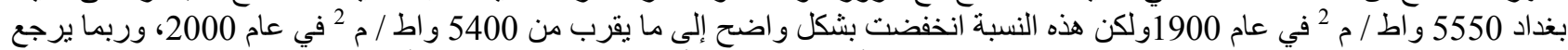

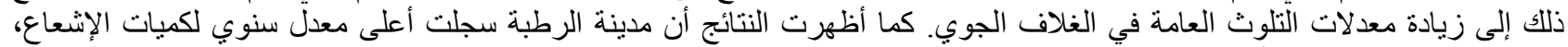

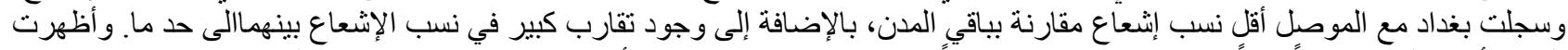

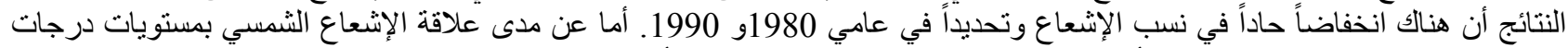

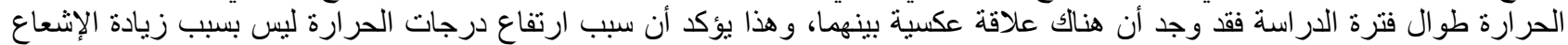

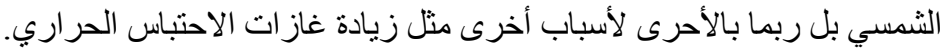

$$
\text { الكلمات المفتاحية:الاشعاع الثمسي المباشر، الاحتباس الحراري، العراق، تذبذب الاشعاع، نمطدرجات الحرارة. }
$$

